nufactura de coroas pelo sistema CAD/CAM (computer-aided design/computer-aided manufacturing) - o método convencional (digitalização do modelo) e o método de digitalização do molde em elastómero - com sistema de leitor digital extraoral. Materiais e métodos: Foi utilizado um modelo Frasaco com duas preparações dentárias para coroa total digitalizado com um scanner industrial de 12 megapixels (GOM Atos Compact Scan 12M), guardado em ficheiro STL (standard tesselation language) e utilizado como modelo de referência. Posteriormente foi realizada uma impressão do modelo Frasaco pela técnica de dupla mistura com polivinilsiloxano (Light Body Type III, Putty Soft Type 0, Zhermack, Rovigo, Italy). A impressão e o modelo Frasaco foram depois digitalizadas 5 vezes no scanner Identica T500 (Medit, Korea) e obtidos os ficheiros STL correspondentes. Os ficheiros obtidos foram sobrepostos com auxílio de um software de análise tridimensional (Geomagic Design X, 3D Systems) através da sobreposição best-fit das áreas totais dos dentes entre o modelo de referência e as digitalizações do modelo e da impressão no scanner Medit T500. A comparação foi realizada com as discrepâncias obtidas entre o modelo de referência e os diferentes métodos sob a forma de média e desvio padrão de Root Mean Square (RMS), sendo definidos valores inferiores a $100 \mu \mathrm{m}$ (micrómetros) como clinicamente aceitáveis. Foi estabelecida uma significância de 0,05. Resultados: As discrepâncias obtidas para o modelo de referência foram de 34,5/-2,10 $\mu \mathrm{m}$ e de 18,42 /-0,48 $\mu \mathrm{m}$ no método de digitalização do molde em elastómero e no método convencional, respetivamente. Foram detetadas discrepâncias estatisticamente significativas entre métodos (Mann-Whitney, $\mathrm{P}<0,05)$. Conclusões: Com base nos resultados deste estudo in vitro foi possível verificar uma tendência para uma maior discrepância na leitura direta do modelo de silicone, no entanto dentro dos valores referenciados na literatura como clinicamente aceitáveis.

http://doi.org/10.24873/j.rpemd.2019.12.609

\section{\#152 Teste de Impacto de novos materiais para protetores bucais}

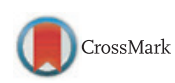

Maria Moreira*, Paulo Reis, Ana Amaro, Ana Messias, João Carlos Ramos

Departamento de Engenharia Eletromecânica da Universidade da Beira Interior, Área da Medicina Dentária da Faculdade de Medicina da Universidade de Coimbra, Departamento de Engenharia Mecânica da Faculdade de Ciências e Tecnologias da Universidade de Coimbra

Objetivos: Etileno Vinil Acetato (EVA) é o material mais utilizado no fabrico de protetores bucais individualizados, mas apresenta algumas limitações como a necessidade de espessuras superiores a $4 \mathrm{~mm}$ para conferir proteção adequada. A laminação das placas de EVA, assim como o uso de outros materiais, pode aumentar a proteção, mantendo ou diminuindo a espessura do protetor bucal, contribuindo para o conforto do atleta. O objetivo deste trabalho foi a avaliar a resistência ao impacto de diferentes placas termomoldáveis laminadas feitas a partir de EVA ou de outros materiais comercialmente disponíveis. Materiais e métodos: Foram pre- parados 5 grupos de placas termomoldáveis $(\mathrm{N}=15)$ para serem submetidos a teste de impacto por queda de peso com energias de 1.72J, 2.85J e 4.40J: G1 (EVA): placas de $4 \mathrm{~mm}$ de EVA; G2 (EVA_SOFT): placas laminadas com $4 \mathrm{~mm}$ de espessura de EVA e núcleo de espuma de EVA (2mm); G3 (EVA HARD): placas laminadas com $4 \mathrm{~mm}$ de espessura de EVA e núcleo semi-rígido de acetato $(0.5 \mathrm{~mm})$; G4 (ERKOLOC): placas semi-rígidas de Erkoloc-pro com 3mm de espessura; G5 (RESIN_IBT): placas maciças de Resina Ortho IBT obtidas por impressão 3D com 4mm de espessura e dureza Shore semelhante ao EVA. A comparação dos grupos foi feita através da análise qualitativa das curvas energia-tempo, força-tempo e força-deslocamento, bem como da análise de variância a um fator das variáveis pico de força, deslocamento máximo, tempo de contato e energia absorvida pelo teste de Kruskal-Wallis, com correção de Bonferroni para comparações múltiplas. Resultados: Diferenças estatisticamente significativas foram encontradas nos valores de energia absorvida das diferentes placas $(p=0.001)$, tendo o ERKOLOC revelado os menores valores de energia absorvida para qualquer energia testada. EVA_SOFT demonstrou os menores valores de força máxima de impacto, mas os maiores valores de deslocamento. RESIN_IBT demonstrou os menores valores de energia elástica. EVA_HARD demonstrou delaminação sob energias de impacto de 4.40J, revelando não ser apropriada para proteção. Conclusões: Verificou-se que a inserção de uma camada intermédia menos rígida que o EVA (EVA_SOFT) é uma boa opção para a confeção de protetores bucais. Materiais rígidos e com menor espessura (ERKOLOC), ainda que exibam elevados níveis de energia elástica, tornam este tipo de placas inadequado devido ao dano provocado. Verificou-se ainda que, segundo os resultados, os materiais tridimensionalmente impressos não são adequados para a confeção de protetores bucais.

http://doi.org/10.24873/j.rpemd.2019.12.610

\section{\#153 Avaliação da postura crânio-cervical: Tratamento com o aparelho funcional do tipo ativador}

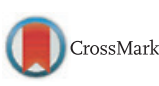

Carla Sofia Correia Vasco*, Maria Ponces, Joana Cristina Silva, Carlos Pires, João Sousa, Eugénio Martins

Faculdade de Medicina Dentária da Universidade do Porto, Escola Superior de Tecnologia da Saúde do Porto - Instituto Politécnico do Porto, Centro de Matemática da Universidade de Trás-os-Montes e Alto Douro (CM-UTAD), Vila Real

Objetivos: Avaliar a influência do tratamento ortodôntico intercetivo na postura crânio-cervical em pacientes com Classe II esquelética em fase de dentição mista, tratados com o aparelho funcional do tipo ativador Teuscher acoplado com forças extra-orais de tração occipital. Materiais e métodos: Neste estudo retrospetivo foram avaliados vinte e quatro pacientes com Classe II esquelética em fase de dentição mista. A análise foi realizada através de telerradiografias faciais em incidência de perfil selecionadas aleatoriamente a partir de uma amostra ortodôntica. Foram estudados em dois tempos T0 e T1 mediante análise cefalométrica com parâmetros sele- 
cionados a partir das análises de Ricketts, de Steiner, Rocabado e Solow e Tallgren. T0 correspondia ao período imediatamente anterior ao tratamento ortodôntico intercetivo e T1, ao término dessa fase. Os dados obtidos foram analisados estatisticamente com o software SPSS ${ }^{\circledR}$ em que se efetuou a avaliação do tipo de distribuição da amostra para testar a normalidade das variáveis recorrendo ao Teste de Shapiro-Wilk, o teste $\mathrm{T}$ de Student para amostras emparelhadas e independentes, e quando não se verificou a distribuição normal, foram usados os testes não paramétricos alternativos (Teste de Wilcoxon e Teste de Mann-Whitney). Considerou-se um nível de significância de 5\%. Resultados: Não se encontraram diferenças significativas nos fatores descritivos da postura crânio-cervical entre T0 e T1. No que respeita ao Arco Mandibular registaram-se diferenças estatisticamente significativas ( $\mathrm{p}=$ 0.005) entre os géneros, na variação de T0 para T1. Conclusões: Não foi possível estabelecer uma relação entre o tratamento com um aparelho funcional do tipo ativador Teuscher e as alterações posturais crânio-cervicais no decorrer da fase intercetiva do tratamento.

http://doi.org/10.24873/j.rpemd.2019.12.611

\#154 Qualidade de vida relacionada com a saúde oral na população sem-abrigo

Maria Teresa Castro*, Maria de Lurdes Lobo Pereira

Faculdade de Medicina Dentária da Universidade do Porto, UpUnit Instituto de Saúde Pública da UP

Objetivos: Este estudo pretende a caracterização da qualidade de vida relacionada com a autoperceção de saúde oral numa população sem-abrigo da cidade do Porto, usando o questionário OHIP-14. Adicionalmente pretendeu-se caracterizar os hábitos relacionados com a saúde oral bem como a autoperceção de saúde oral nesta amostra de população sem-abrigo. Materiais e métodos: A amostra foi constituída por 36 indivíduos sem-abrigo com idades compreendidas entre os 24 e os 76 anos. Os dados da amostra foram obtidos através da aplicação de um questionário em entrevista. O questionário utilizado divide-se em 4 secções distintas: parâmetros sociodemográficos, hábitos de higiene oral, autoperceção de saúde oral e o questionário OHIP-14. Recorrendo-se ao IBM SPSS Statistics $25^{\circledR}$, foram realizadas estatísticas descritivas da amostra para caracterização da amostra. Resultados: Os itens individuais que apresentaram impacto foram 'desconforto ao comer", "menor satisfação com a vida", "sentir constrangimento" e "sentir complexos". Dos 7 domínios, o da dor física foi o que apresentou maior prevalência de impactos $(61,1 \%)$. O valor médio total do OHIP-14 foi de 15,5 $\pm 1,8$. Conclusões: Tendo em conta os resultados obtidos, existe a necessidade de educação sobre saúde oral na população sem-abrigo de forma a melhorar os seus hábitos de higiene oral e a maneira como encaram a saúde oral, bem como o continuar a desenvolver o Serviço Nacional de Saúde na área da medicina dentária com o intuito de diminuir as morbilidades associadas a esta população e, consequentemente aumentar a qualidade de vida.

http://doi.org/10.24873/j.rpemd.2019.12.612
\#155 Saúde oral e seus determinantes numa população pré-escolar - Programa de escovagem diária

Margarida Maria Ferraz Martins de Almeida Maia*, Maria João Costa Rodrigues Pires, Henrique de Mesquita Guimarães e Ferreira Cardoso, ML Pereira

Faculdade de Medicina da Universidade do Porto, EpiUnit Instituto de Saúde Pública da UP

Objetivos: Este trabalho teve como objetivo a caracterização dos hábitos de higiene oral das crianças do pré-escolar e dos seus determinantes, assim como a avaliação do efeito de um programa de escovagem diária na escola no estado de saúde oral (índice de placa bacteriana e história passada e presente de cárie) nas mesmas. Materiais e métodos: Esta investigação foi realizada em crianças com idades entre os 2 a 6 anos, pertencentes ao Centro Escolar de Cabanelas, do Agrupamento de Escolas de Prado. Para a concretização do estudo, existiram dois momentos distintos: o primeiro incluiu uma entrevista aos Encarregados de Educação, com recurso a um questionário estruturado e aplicado pela investigadora, e a realização de um exame clínico aos participantes do estudo. Neste questionário foram avaliadas características sociodemográficas, entre as quais o ano de escolaridade da mãe e do pai, dados pessoais da criança (sexo, nome e data de nascimento), questões relacionadas com os hábitos alimentares das crianças (frequência e momento de consumo de alimentos com potencial cariogénico) e hábitos relacionados com a higiene oral (frequência e momento de escovagem, acompanhamento na escovagem, tipo de escova, forma e momentos de utilização do dentífrico fluoretado). Foi ainda introduzida a escovagem diária na escola, depois do almoço, entre janeiro de 2019 e março de 2019. O segundo momento consistiu na realização de um novo exame clínico, para avaliação da repercussão da implementação da escovagem. O diagnóstico de cárie foi realizado através dos critérios do ICDAS II, e o índice de placa foi avaliado através do Índice de Pass. Resultados: A amostra apresentou uma percentagem de prevalência de cárie dentária de 51,7\%. Verificou-se uma diferença significativa no índice de placa após a implementação da escovagem, tendo este reduzido de $73,28 \%$ para $31,72 \%$. Conclusões: Através dos resultados obtidos, concluiu-se que a escovagem diária foi eficaz na redução do índice de placa das crianças do pré-escolar. Apesar das limitações deste estudo, parece ser possível concluir que a implementação da escovagem diária na escola é uma mais valia para a saúde oral das crianças, uma vez que reduz significativamente a placa bacteriana. http://doi.org/10.24873/j.rpemd.2019.12.613

\#156 Saúde oral e o impacto na qualidade de vida numa população pré-escolar em Salvador - Bahia

Coutinho MI*, Moura ML, Cangussu MC, Pereira ML

Faculdade de Medicina Dentária da Universidade do Porto, Faculdade de Odontologia da Universidade Federal da Bahia, EpiUnit

Objetivos: O objetivo deste estudo é avaliar o impacto da cárie, trauma e má oclusão na qualidade de vida das crianças 